\title{
Aplicaciones didácticas del género citación judicial en la traducción jurídica alemán-español
}

\author{
Teaching Applications of the Genre Court Summons in German-Spanish Legal Translation \\ Aplicações didáticas do gênero citação judicial na tradução jurídica alemão-espanhol
}

Francisco J. Vigier Moreno* (https://orcid.org/0000-0002-0996-2578)

Departamento de Filología y Traducción, Universidad Pablo de Olavide, Sevilla, España
Recibido: 29-09-17

Revisado: 02-11-17

Aceptado: 23-11-17

Publicado: 18-12-17

RESUMEN. Esta experiencia docente, diseñada e implementada para la formación universitaria en traducción jurídica del alemán (como segunda lengua extranjera o lengua C) al español (primera lengua o lengua A), describe las aplicaciones didácticas derivadas de la explotación de un encargo de traducción, simulado pero realista, de una cédula de citación alemana al español. Siguiendo los postulados de las teorías de género textual (Borja, 2013; Orts, 2017) aplicados al análisis pre traductológico de la situación comunicativa en traducción jurídica (Prieto, 2013), los estudiantes puedan desarrollar su competencia en traducción jurídica y elaborar un marco de toma de decisiones (Way, 2014) que les permita justificar las soluciones que ofrecen a los problemas de traducción identificados. De este modo, profundizan en su especialización en la traducción jurídica alemán-español con mayor autonomía y autoconfianza, al cobrar mayor consciencia de los factores que influyen en la idoneidad de las decisiones adoptadas por un traductor jurídico.

Palabras

clave:

formación;

traducción;

derecho

comparado;

alemán;

español.

ABSTRACT. This teaching experience was designed for and implemented in a university

Keywords:

training,

translation, C language) - Spanish (first language or A language) language pair. It describes the applications of a simulated yet realistic project, whereby students were asked to 
translate a German court summons into Spanish. Following the main theories on textual genre (Borja, 2013; Orts, 2017), as applied to the pre-translation analysis of the communicative situation in legal translation (Prieto, 2013), trainee translators are able to develop their legal translation competence and to establish a decision-making framework (Way, 2014) that allows them to justify their solutions to the translation problems identified. Accordingly, they can continue their specialization in the translation of legal texts from German into Spanish with greater autonomy and self-confidence, by developing greater awareness of factors influencing the adequacy of decisions taken by the legal translator. comparative law, German,

Spanish

RESUMO. Esta experiência de ensino, desenhada e implementada para a formação universitária em tradução jurídica de alemão (como segunda língua estrangeira ou língua C) ao espanhol (primeira língua ou língua A), descreve as aplicações didáticas derivadas da exploração de um encargo de tradução, uma simulação bastante realista, de um mandato de citação alemão para espanhol. Seguindo os postulados das teorias do gênero textual (Borja, 2013; Orts, 2017) aplicados à análise pré-tradutológica da situação comunicativa em tradução jurídica (Prieto, 2013), os alunos podem desenvolver

$$
\begin{array}{r}
\text { Palavras- } \\
\text { chave: } \\
\text { formação, } \\
\text { tradução; } \\
\text { direito } \\
\text { comparado, } \\
\text { alemão, } \\
\text { espanhol }
\end{array}
$$
sua competência em tradução jurídica e desenvolver um quadro de tomada de decisões (Way, 2014) que thes permite justificar as soluções que oferecem aos problemas de tradução identificados. Desta forma, eles aprofundam sua especialização na tradução jurídica alemão-espanhol com maior autonomia e autoconfiança, à medida que se tornam mais conscientes dos fatores que influenciam na idoneidade das decisões adotadas por um tradutor jurídico.

\section{CONTEXTO INSTITUCIONAL Y CURRICULAR}

En la mayoría de los programas de formación universitaria de traductores en el mundo occidental, siguiendo las exigencias de las principales instituciones internacionales de traducción e interpretación (en adelante, TI), los estudiantes cursan sus estudios con dos lenguas de trabajo extranjeras (siguiendo la terminología de la Asociación Internacional de Intérpretes de Conferencia, lengua $\mathrm{B}$ y lengua $\mathrm{Cl}$ además de la lengua principal (o lengua $\mathrm{A}$ ), entendiéndose la lengua $\mathrm{C}$ como una lengua desde la que el futuro egresado debe ser capaz de traducir hacia la lengua $A$, pero no a la inversa. De forma muy similar a la mayoría de titulaciones en TI a nivel de grado en el contexto universitario español (e incluso europeo), el Grado de Traducción e Interpretación (GTI) de la Universidad Pablo de Olavide (UPO) establece, de forma análoga, la elección de una lengua $B$ (inglés, francés o alemán) y de otra lengua C la elegir entre inglés, francés, alemán, italiano y árabe), en combinación con la lengua A (español). 
Entre los estudiantes del GTI con inglés como lengua B (el grupo más numeroso, por otra parte), desde hace unos años la combinación alemán-español se ha convertido, sin lugar a dudas, en la de mayor demanda. Teniendo en cuenta que la lengua $C$ se aprende en el GTI ab initio, no es de extrañar que los primeros dos cursos de estos estudios cuatrienales se dediquen, fundamentalmente, a la enseñanza de la lengua $C$ en sí (27 créditos ECTS') y de la civilización de sus respectivos países (12 créditos ECTS) (VERIFICA GTel, 2010). No obstante, con el fin de que los estudiantes egresen capaces de traducir al español textos, tanto generales como especializados, redactados en dos lenguas extranjeras, el plan de estudios comprende cuatro materias obligatorias en traducción, a saber, Introducción a la Traducción de la Lengua C (textos generales, 6 créditos ECTS), Traducción de Software y Páginas Web C (6 ECTS), Traducción Especializada C I (6 ECTS) y Traducción Especializada C/l (6 ECTS)².

Este contexto institucional y curricular, por tanto, establece el gran reto docente de formar traductores de textos especializados (de los cuatro campos principales: científico, técnico, económico y jurídicol en la combinación alemán-español C-A por medio de tan solo dos asignaturas. A continuación, partiendo de una reflexión sobre los principales fundamentos, objetivos y condicionantes de la formación en traducción jurídica y las aplicaciones didácticas de los enfoques basados en el concepto de género textual y del análisis pretraductológico en traducción jurídica, presentamos una experiencia docente desarrollada en el seno de una de estas asignaturas de traducción especializada alemánespañol: la explotación didáctica de un encargo de traducción al español de una cédula de citación judicial alemana, que, como mostramos, permite sistematizar las competencias que se pretende que desarrolle el estudiantado gracias a una eficaz metodología docente orientada al proceso traductológico y al establecimiento de un marco eficaz de toma de decisiones.

\section{LA ENSEÑANZA DE LA TRADUCCIÓN JURÍDICA: FUNDAMENTOS, OBJETIVOS Y CONDICIONANTES}

La traducción jurídica es un campo de especial complejidad dentro de la práctica de la traducción, como han expuesto muchos autores (como Alcaraz \& Hugues, 2002, por citar algunos). La traducción de textos jurídicos constituye un acto comunicativo entre dos lenguas dentro de un ámbito de especialidad específico, con sus correspondientes conocimiento, discurso y terminología especializados, pero, además, en los casos de traducción jurídica intersistémica, se caracteriza fundamentalmente por la ausencia de referencias universales comunes entre los dos sistemas lingüísticos, culturales y nocionales en liza, es decir, por las archinombradas asimetría jurídica e incongruencia terminológico-conceptual. Debido a esta falta de equivalencias entre los diferentes ordenamientos y discursos jurídicos, el traductor se ve obligado a emprender un arduo proceso de toma de decisiones y de aplicación de estrategias y técnicas de traducción en función del contexto comunicativo en que se produzca el encargo y del grado de adecuación de las distintas opciones que se le presentan respecto de la finalidad de la traducción (determinadas por el skopos), todo ello sobre la base de un estudio comparativo temático y discursivo (es decir, de derecho y textología comparados).

\footnotetext{
1 Cabe recordar que 1 crédito ECTS supone unas 25-30 horas de actividad para el estudiante, incluyéndose las horas lectivas, de estudio y trabajo autónomo, tutorías, seminarios, prácticas, etc., además de las invertidas en preparar y realizar las pruebas de evaluación establecidas.

2 Los estudiantes también pueden completar su formación en esta combinación lingüística con las asignaturas Traducción Editorial C, Técnicas de Traducción Inversa C e Interpretación Bilateral C/A/C, de carácter optativo.
} 
A pesar del alto grado de especialización que requiere este campo traductológico, el continuo aumento de las relaciones jurídicas internacionales trae consigo una correlativa creciente demanda en el mercado de traducciones de textos de naturaleza jurídica. De ahí la incuestionable necesidad de formar en las universidades a traductores jurídicos competentes, es decir, que sepan ejercer la profesión de traductor jurídico con la profesionalidad, la pericia y la deontología necesarias. En los últimos años la formación basada en competencias se ha impuesto como paradigma formativo en la disciplina de la TI (Hurtado Albir, 2007), sobre la base de propuestas de descripción y sistematización de las habilidades, conocimientos, destrezas y aptitudes que conforman la macrocompetencia traductora (EMT Expert Group, 2009; Kelly, 2007; PACTE, 2000, por citar solo algunos).

En el caso específico de la traducción jurídica, también en los últimos años se han ofrecido modelos que desglosan los componentes competenciales que deben guiar los programas formativos de traductores jurídicos (Cao, 2014; Piecychna, 2013; Prieto, 2011, 2013; Scarpa \& Orlando, 2017). Sintetizando estas propuestas sobre la base del modelo multicompetencial de Prieto (ob. cit.), la competencia en traducción jurídica puede desglosarse en los siguientes componentes fundamentales, todos interrelacionados y mutuamente influenciables:

1) Competencia estratégica o metodológica: encargada de dirigir la aplicación de las demás y entendida como "the integrated mental ability inherent in the translation task when a translator carries out an operation on a text and enacts language and knowledge competence for communicative purposes in translation" (Cao, 2014, p. 113), comprende la organización general del proceso, el análisis del encargo, la ubicación macrotextual de los textos origen y meta, la identificación de problemas de traducción, la toma de decisiones para su resolución (aplicación de técnicas), la revisión, la autocrítica y la toma de conciencia sobre "one’s own limitations and posible lack of skills" (Piecychna, 2013, p. 153).

2) Competencia lingüística y textual: abarca el dominio de la lengua origen y meta, así como de sus discursos jurídicos, incluyendo el análisis contrastivo de rasgos textuales y convenciones de géneros textuales jurídicos, con el fin de, entre otros, ser capaz de "compose a document in accordance with the conventions of the genre and rhetorical standards" (Scarpa \& Orlando, 2017, p. 30).

3) Competencia temática y cultural: "a distinctive feature of legal translator competence" (Prieto, 2011, p. 12), envuelve los conocimientos jurídicos (ordenamientos, ramas y fuentes del derecho), con especial hincapié en la concienciación sobre las asimetrías jurídicas y los mecanismos básicos del derecho comparado aplicados a un encargo de traducción concreto.

4) Competencia instrumental (documental y tecnológica): de enorme trascendencia, pues "how much a translator knows is no longer as important as knowing how to find reliable information and filter, select, and use it correctly" (Way, 2016, p. 1015), engloba el dominio de los recursos documentales especializados, la gestión documental y terminológica, y el uso de herramientas informáticas. 
5) Competencia interpersonal y profesional: comprende la habilidad del trabajo colaborativo, la capacidad de planificación y ejecución de un proyecto, las habilidades interpersonales y el conocimiento del marco jurídico y de la deontología del ejercicio profesional.

Habida cuenta de lo anterior, no son pocos los objetivos formativos que ha de marcarse un docente de la traducción jurídica. Asimismo, como todo proceso formativo, la enseñanza de esta modalidad translativa se halla condicionada por una serie de factores que influyen en el contexto en que tiene lugar, como el número de horas lectivas, el nivel de conocimientos de los alumnos, los recursos disponibles, etc. Way (2016) expone dos razones fundamentales que explican las dificultades encontradas por los estudiantes noveles de traducción jurídica: en primer lugar, una obsesión por parte de los estudiantes respecto del nivel microtextual (palabras), especialmente en lo relativo a la terminología en etapas formativas iniciales; en segundo lugar, su exigua experiencia vital ly, por ende, su frecuente desconocimiento de los campos temáticos jurídicos). Esta inseguridad y falta de conocimiento, además, hace que muchos estudiantes de TI apliquen enfoques fundamentalmente literalistasa su praxis traductora. De esta manera, como apuntan Calvo y Ortega (2010), las traducciones efectuadas por los aprendices de traducción jurídica muy a menudo se quedan ancladas en el marco microtextual y no progresan "hasta el punto de integrar la verdadera dimensión macrotextual (función del documento y significado global) y extratextual (receptor, entorno comunicativo, efectos jurídicos) de que goza todo el texto" (p. 66).

En el caso de nuestra experiencia docente, a estos condicionantes hemos de sumarle otro específico relacionado con la direccionalidad: la traducción C-A. Así, muchos de nuestros estudiantes presentan graves problemas de comprensión de los textos originales (jurídicos, redactados en alemán) como consecuencia de sus carencias, no ya en competencia temática sino en mera competencia lingüística de su lengua $\mathrm{C}$ (alemán), ya que han de enfrentarse a esta práctica habiendo recibido, siendo optimistas, una formación lingüística previa conducente a la adquisición del nivel B2 del Marco Común Europeo de Referencia para las Lenguas (VERIFICA GTel, 2010, p. 16).

\section{El género textual y la toma de decisiones aplicados a la formación de traductores jurídicos}

En las dos últimas décadas de florecimiento en la investigación en traducción jurídica parece haberse consolidado la investigación basada en el derecho y la textología comparados como marco metodológico previo al proceso traductor y de referencia durante el mismo. Así, son numerosas las aportaciones que se han llevado a cabo en traducción jurídica con diferentes tipologías textuales, combinaciones lingüísticas y ordenamientos jurídicos como objeto de estudio -por citar solo algunos a suerte de ejemplo, Borja (2013), Campos (2017), De las Heras (2015), Holl (2011), Orts (2017), Soriano (2004) y Wiesmann (1999).

Este enfoque se basa, a su vez, implícita y explícitamente, en el concepto de género textual en tanto que manifestación estructurada y convencionalizada de un acto comunicativo dentro de una comunidad discursiva específica que persigue unos fines comunicativos concretos (Bhatia, 1993, p. 13). La identificación del género textual tanto del texto origen como del texto meta permite al traductor, por un lado, caracterizar el texto (origen) y conocer los mecanismos retóricos y pragmáticos, así como los 
propósitos comunicativos de la comunidad discursiva de la que surge (Borja, 2013, p. 35) y, por el otro, establecer similitudes con géneros de la lengua y la cultura meta (que funcionan, como es bien sabido, como textos paralelos). Es, precisamente, mediante ese análisis comparativo entre el género textual origen y el género textual meta cómo se pueden establecer similitudes y desemejanzas no solo entre los textos en sí (de naturaleza lingüística, terminológica, textual, macroestructural, etc.) sino entre los ordenamientos jurídicos de referencia que se materializan en cada uno de ellos (Holl, 2011).

La aplicación de esta metodología a la docencia de la traducción jurídica resulta de una utilidad incuestionable por las siguientes razones. En primer lugar, los géneros jurídicos son paradigma de estructuración estereotipada y repetitiva, lo que facilita su sistematización y análisis discursivos (Orts, 2017, p. 227). En segundo lugar, el reconocimiento de elementos a nivel terminológico, textual y conceptual en el texto origen gracias a su identificación como género favorece su comprensión y el posterior análisis del texto meta. En tercer lugar, el establecimiento de semejanzas y, sobre todo, diferencias terminológicas, discursivas y conceptuales entre el género textual de la cultura origen y el de la cultura meta obligan al traductor a realizar un ejercicio comparativo de ubicación textual y contextualización temática (textología y derecho comparados).

Como es bien sabido, la traducción es una actividad que se fundamenta en la toma de decisiones. Según Prieto (2011, p. 18), es precisamente en este proceso de toma de decisiones en el que más hincapié ha de hacerse en las primeras etapas de la enseñanza de la traducción jurídica, promoviéndose una reflexión sistemática entre los traductores en formación que contribuya al desarrollo y consolidación de su competencia estratégica (de la que, recordemos, dependen el resto de competencias) y, por ende, de su autoconfianza, ya que sin este ejercicio reflexivo es fácil optar por soluciones erráticas o superficiales.

En una interesante y valiosa adaptación de la Teoría de la Toma de Decisiones a la práctica traductora, Way (2014, p. 141) establece los siguientes pasos en el proceso de toma de decisiones en traducción jurídica: 1) establecimiento de la situación comunicativa o skopos (la decisión global); 2) identificación y categorización de los problemas de traducción, con el fin de seleccionar las destrezas subcompetenciales necesarias para resolver cada uno de ellos; 3) análisis de posibles soluciones y sus consecuencias en el texto meta; 4) elección de la mejor opción o solución para cada problema; 5) aplicación del procedimiento global (course of action), una vez tomada la decisión, y evaluación de las repercusiones de la solución seleccionada.

La experiencia docente que presentamos en estas líneas, se basa en estos dos enfoques de género textual y de toma de decisiones, con un doble objetivo: por un lado, que, mediante el análisis pretraductológico de alcance textual y temático, los estudiantes dispongan de mayores elementos de juicio para tomar decisiones más justificadas al momento de acometer el encargo de traducción jurídica; por otro lado, que los estudiantes sistematicen y (con el tiempo) automaticen un método de trabajo que les proporcione autonomía mientras progresan en su especialización en la traducción jurídica alemán-español. 


\section{Aplicaciones formativas del encargo de traducción de una citación judicial alemana al español}

En esta actividad, los estudiantes reciben el siguiente encargo (simulado pero basado en la realidad judicial y en los procesos habituales en este contexto profesionall ${ }^{3}$ : el destinatario de este documento (ver Apéndice A), un ciudadano español residente en Alemania, tiene conocimientos limitados de la lengua alemana y, por tanto, solicita su traducción al español ${ }^{4}$. En la siguiente sesión presencial, se ponen en común los resultados del análisis pretraductológico realizado por los estudiantes lque se detalla a continuación) y se eligen al azar las traducciones realizadas por dos estudiantes, sobre cuya evaluación -por pares y por parte del docente- se genera un interesante debate acerca de las soluciones ofrecidas y su justificación.

Con el fin de que puedan sistematizar su labor traductora, reflexionar sobre su toma de decisiones y, con el tiempo, automatizar buenas prácticas, se pide a los estudiantes que sigan las pautas metodológicas para la traducción de textos jurídicos propuestas por Prieto (2013), que incluyen los siguientes pasos: 1) Análisis del encargo de traducción y de la situación comunicativa: tipo de traducción (instrumental o documental), situación comunicativa del texto origen y función del texto meta (skopos), etc.; 2) Ubicación macrotextual de la operación traductora: ordenamientos jurídicos (coordenadas jurisdiccionales y lingüísticas), ramas del derecho (coordinadas temáticas y normativas) y tipologías y géneros (coordenadas procedimentales y discursivas) ${ }^{5}$; 3 ) Análisis del texto origen, con especial atención a los problemas de comprensión y ambigüedad, las figuras jurídicas singulares y el grado de formulismo; 4) Reformulación (elaboración del texto meta): ante los problemas terminológicos y fraseológicos, análisis de necesidades y expectativas de los receptores y análisis de la aceptabilidad de formulaciones según tipo y grado de correspondencia, con el fin de aplicar posteriormente las correspondientes técnicas de traducción; 5) Revisión (comprobación de la adecuación de las opciones elegidas al skopos y a las normas de calidad).

Como puede apreciarse, existe una clara convergencia entre estas pautas metodológicas y las fases sobre el proceso de toma de decisiones en traducción jurídica identificadas por Way (2014), lo que nos asegura un desarrollo, una activación y, con el transcurso del tiempo, una consolidación de las destrezas y competencias que marcan nuestro proceso formativo. Así, por ejemplo, mientras que el análisis del encargo y la revisión estimulan la competencia estratégica, la ubicación macrotextual fomenta la competencia temática y cultural (coordinadas temáticas y normativas) y la competencia lingüística y textual (coordenadas discursivas). Exteriorizando todos estos procesos, los estudiantes cobran consciencia de lo aprendido de una manera reflexiva y justificada y elaboran su propio marco de toma de decisiones, lo que les permite continuar avanzando en su especialización en la traducción jurídica alemán-español de manera autónoma y con mayor confianza en sí mismos.

\footnotetext{
3 Siguiendo, pues, los principios de formación situada y andamiaje defendidos por Calvo (2015) en la formación de traductores.

4 Si fueran las autoridades judiciales alemanas las que encargaran la traducción, se debería pedir a un traductor autorizado o jurado de conformidad con la legislación alemana; para conocer más sobre la organización de la profesión de traductor jurado en Alemania, ver Vigier Moreno (2010).

${ }^{5}$ Este paso coincide en gran medida con el modelo de análisis textual multinivel propuesto por Valderrey (2017), que comprende un nivel situacional, un nivel funcional, un nivel semántico y un nivel formal que fomenta la activación de las competencias temática e instrumental (documental) del aprendiz de traducción jurídica al combinar el análisis textual contrastivo con el ejercicio jurídico comparado.
} 
A continuación ilustramos las aplicaciones didácticas que este encargo en concreto ofrece a los estudiantes que reciben formación en traducción jurídica al español del alemán como lengua $\mathrm{C}$ en el $\mathrm{GTI}^{6}$ en dos niveles fundamentales: el macroestructural (identificación textual, función textual, situación comunicativa y temática del texto) y microestructural (aspectos terminológicos, fraseológicos y gramaticales), siguiendo el modelo descrito por Holl (2011, p. 197).

\section{NIVEL MACROESTRUCTURAL}

En cuanto a la situación comunicativa, con una primera lectura del texto se puede identificar que un órgano jurisdiccional alemán (emisor) le ha remitido este documento a un ciudadano español (receptor) en el que le comunica que debe presentarse ante el tribunal un día y hora señalados, incluidas una serie de instrucciones y advertencias. Como funciones principales del texto destacan la apelativa y la informativa. Además, teniendo en cuenta el encargo, se puede colegir que se trata de una traducción documental o informativa, es decir, una traducción cuyo fin principal consiste en transmitir en la lengua meta el mensaje del texto original y no en funcionar como instrumento jurídico en sí inserto en el ordenamiento jurídico meta. Por lo tanto, no caben estrategias domesticadoras del texto, pues el ordenamiento jurídico de referencia del texto meta seguirá siendo el alemán ${ }^{7}$, y puede empezar a plantearse una estrategia más descriptiva habida cuenta del perfil del destinatario del texto meta Imuy probablemente, sin conocimientos sobre el ordenamiento jurídico alemán y sin tener que ser un experto en derecho ni en discurso jurídicol.

Como exponemos a continuación, para la correcta ubicación macrotextual de la operación traductora han de activarse o desarrollarse la competencia temática y cultural y la competencia lingüística y textual. En nuestro encargo se pueden identificar las siguientes coordinadas jurídicas y lingüísticas: el texto origen es reflejo del ordenamiento jurídico alemán y, por tanto, se encuentra redactado en alemán de Alemania lesto se infiere por el propio encargo y por elementos presentes en el texto como el del órgano jurisdiccional emisor, el Amtsgericht Köln); a su vez, el texto meta seguirá refiriéndose al mismo ordenamiento jurídico, redactado, eso sí, en español de España.

En cuanto a las coordenadas temáticas y normativas, el texto origen tiene lugar dentro de la jurisdicción penal, pues elementos como "Strafsachen gegen Beleidigung" nos indican que se trata de una causa penal por la comisión de un delito. En este punto, resulta muy conveniente pedir a los estudiantes, que no suelen tener un conocimiento jurídico relevante previo, que realicen una contextualización nocional de esta rama del derecho (tanto general como específica del ordenamiento jurídico alemán) que favorezca la correspondiente adquisición de conocimientos básicos que, a su vez, le facilitarán la comprensión y análisis del texto origen. Así, se les puede recordar que el derecho

\footnotetext{
6 Debido a las evidentes limitaciones espaciales, en este artículo destacamos los elementos analizados de la citación judicial alemana, aunque hagamos referencia en ocasiones a la española; para una aproximación más profunda sobre la citación judicial española como objeto de traducción, ver Prieto (2002).

7 Como exponemos más adelante, la identificación de estos elementos, que puede parecer a priori intranscendente, condicionará la posterior toma de decisiones respecto de unidades microtextuales. Así, el hecho de que se trate de una traducción documental invalida ya, por ejemplo, el planteamiento de técnicas de traducción como la adaptación les decir, traducir un elemento del ordenamiento jurídico origen por un elemento propio del ordenamiento jurídico metal a la hora de resolver determinados problemas microtextuales, como la traducción de juriculturemas.
} 
penal se refiere a los delitos y las penas y que es el Estado, a través de la autoridad pertinente, el que ejerce la labor de instrucción y enjuiciamiento de la causa, por lo que es de esperar que se encuentren los siguientes actores del procedimiento penal alemán: un acusado (Angeklagter) -en este caso, el destinatario del texto original, como se desprende de "Ihre Strafsache"-; muy probablemente, su representación letrada (Verteidiger); un fiscal (Staatsanwalt); un juez que dirigirá el proceso y dirimirá la causa (Richter); y unos testigos a los que se les tomará declaración durante el juicio (Zeugen).

Además, para el traductor ly más aún para el estudiante), también resulta no solo muy enriquecedor sino necesario ubicar procesalmente el acto al que hace referencia el texto origen. En este caso, este texto se produce en los prolegómenos del juicio oral (Hauptverhandlung). Así, se deduce que la fase de instrucción previa ya ha finalizado, que se ha iniciado la de enjuiciamiento (Eröffnung des Hauptverfahrens), que esta fase finalizará con una sentencia condenatoria (Verurteilung) o absolutoria (Freispruch) y que, por tanto, el sujeto al que se le imputa la comisión del delito no recibe ya la calificación de sospechoso (Beschuldigter) ni investigado (Angeschuldigter), sino la de acusado (Angeklagter), pues la apertura del juicio supone la aceptación de la acusación formulada por la fiscalía (Staatsanwaltschaft).

Para establecer las coordenadas procedimentales y discursivas es necesario identificar el género textual del texto origen, para lo que, obviamente, entran en juego los enfoques traductológicos basados en el género textual a los que hemos hecho referencia con anterioridad. En nuestro caso, el texto que se ha de traducir es claramente una cédula de citación judicial de Alemania, que en alemán se conoce por (Gerichts-) Ladung. Al tratarse de un género jurídico altamente estereotipado, con un sencillo ejercicio de recopilación de textos paralelos en la lengua origen, los estudiantes pueden identificar las diferentes partes en que se estructura dicho género ly las principales funciones comunicativas que desempeñan): emisor; destinatario; denominación del documento; motivo de la comparecencia; fecha, hora y lugar; remisión a un anexo; advertencia sobre el incumplimiento; instrucciones; y fórmula de cierre (con firma) ${ }^{8}$. Además, es un género textual con una escasa extensión (generalmente, una página) y de una relativa sencillez temática en comparación con otros géneros jurídicos (como las sentencias). Esto permite trabajar en clase con un texto íntegro y utilizar el mismo género relativo a jurisdicciones y etapas procesales diferentes (por ejemplo, se puede trabajar en una sesión posterior en un encargo de traducción de una citación judicial para la comparecencia, esta vez, en la vista relativa al recurso de la misma causa). Así, se puede realizar una secuenciación y progresión de la formación que favorezca la consolidación de las competencias ya desarrolladas (Way, 2014, p. 144).

Junto con esto, la identificación de este género y su contextualización en el ordenamiento jurídico origen (alemán) debe conducir a la confirmación de que, como ocurre con muchos géneros jurídicos, existen disposiciones normativas respecto de su redacción lo metagéneros, en palabras de Borja, 2013, pp. 38-39), lo que señala, a su vez, otra característica propia de los géneros jurídicos: la intertextualidad (Orts, 2017) . Esta intertextualidad se hace patente, además, en la referencia que hay en el texto a la

\footnotetext{
8 Esta clasificación de partes del género de la citación judicial en alemán coincide, en gran manera, con el propuesto por Wiesman (1999, p. 169) para las citaciones en procedimientos civiles.

9 La citación relativa a la declaración del acusado en el juicio oral se rige por lo dispuesto en el artículo 216 de la Ley de Procedimiento Penal alemana (Strafprozessordnung).
} 
resolución judicial con la que se ha dado apertura al juicio oral -y que se presenta como anexo en el texto original-y se puede entender de manera implícita con otros géneros del proceso penal, como la denuncia o el escrito de acusación.

\section{NIVEL MICROESTRUCTURAL}

Evidentemente es a este nivel al que se le acaba dedicando más tiempo en clase durante la corrección, si bien muchos de los problemas microestructurales pueden resolverse de manera más adecuada, si previamente se han identificado correctamente algunos de los factores extratextuales del nivel macroestructural. Por limitación espacial presentamos los elementos que pueden explotarse didácticamente con nuestro encargo de manera general y con algunos ejemplos que sirvan de ilustración.

En la cédula de citación alemana se pueden encontrar muchas de las características propias del discurso jurídico alemán, para cuya comprensión y posterior redacción ha de activarse, fundamentalmente, la competencia lingüística y textual. Siguiendo la clasificación de Cobos (2012, pp. 48-53), estos son algunos de los rasgos identificados:

- Nivel morfosintáctico: preferencia por la yuxtaposición frente a la subordinación oracional ${ }^{10}$; fórmulas de cortesía (p. ej., “bitte”y "mit freundlichen Grüßen")"11 ; uso de verbos modales (“im Gerichtssaal sein können"o "müssen Sie zum Termin kommen"); frecuente uso del imperativo, relacionado con la función apelativa del texto ("Richten Sie", "Führen Sie", "Beachten Sie", etc.) 12; uso de la voz pasiva, para trasladar el carácter impersonal del texto ("werden Sie ... geladen" o "wird ... ein Haftbefehl erlassen"); y profusión de sintagmas preposicionales, muchos de los cuales constituyen frasemas del alemán jurídico lauf Anordnung + genitivo o im Falle + genitivo), entre otros.

- Nivel léxico-semántico: profusión de composición léxica neológica l $p$. ej., "Verhandlungsunfähigkeit"); prolija adverbialización ("umgehend", "grundsätzlich", "regelmäßig", etc.); nominalización ("unentschuldigten Ausbleibens" o "(Ihre) poliziliche Vorführung"); amplia presencia de términos jurídicos ("Strafsache", "Beleidigung", "Hauptverhandlung", "Beschluss" o "Hauptverfahren", por ejemplo)13 ; y lo que nosotros denominamos juriculturemas, es decir, "figuras jurídicas que se pueden considerar específicas de un sistema concreto y ajenas a la realidad de la tradición jurídica de los receptores [del texto meta]" (Prieto, 2013, p. 94), como “Amtsgericht”, “Geschäftstelle” y “Justizbeschäftigte”.

\footnotetext{
10 Frente a la abundancia de subordinación en la cédula de citación española.

11 En español, la cortesía y formalidad del discurso jurídico se expresan con otros mecanismos.

12 En contraste con el uso habitual de la tercera persona en los textos paralelos españoles.

13 Para la traducción de estos términos jurídicos, que pueden (o no) tener una equivalencia clara en el español, se alerta a los estudiantes de las limitaciones de los diccionarios bilingües convencionales (especializados y, más aún, generales), que suelen ofrecer diferentes opciones de traducción (generalmente) descontextualizadas y sin indicaciones sobre la técnica de traducción utilizada; por tanto, se les recomienda, nuevamente, llevar a cabo microestudios de derecho comparado partiendo de la delimitación conceptual monolingüe del término origen y comparándola con la definición conceptual de las distintas opciones planteadas para su traducción en la lengua meta y su grado de adecuación al encargo concreto.
} 
Para ilustrar cómo los diferentes pasos de la actividad docente ayudan a que el alumno tome decisiones que se adecuen mejor a la situación comunicativa, activando diferentes conocimientos, destrezas y habilidades, vamos a exponer la solución propuesta para Amtsgericht en este encargo en concreto. En primer lugar, partimos de su definición en alemán ${ }^{14}$, para delimitar conceptualmente este término. Una vez conocidas sus características y función, se buscan distintas opciones de traducción y se evalúa su grado de adecuación en función de la contextualización realizada, que permite al estudiantado ser más crítico, por ejemplo, con las opciones de traducción que encuentre en las fuentes lexicográficas bilingües más habituales, todo lo cual, a su vez, no deja de ser un ejercicio de activación de competencia traductora (estratégica, en cuanto al proceso, y documental, en cuanto a las fuentes).

Volviendo al caso de Amtsgericht, estas son algunas de las opciones que ofrecen tres de los recursos que los estudiantes suelen usar con mayor asiduidad: “juzgado de primera instancia e instrucción” y “juzgado municipal” (Diccionario en línea PONS ${ }^{15}$ ); “tribunal de primera instancia”, “Juzgado Municipal”, “Juzgado Comarcal" y "Tribunal municipal" (IATE ${ }^{16}$ ); y "juzgado local" y "juzgado municipal" (Becher \& Schülter-Ellner, 2017). Así, teniendo en cuenta los resultados del análisis realizado en el plano macroestructural que hemos detallado en el apartado anterior, descartamos opciones adaptativas como “juzgado de primera instancia e instrucción". Tampoco parece tener mucho sentido hablar de "juzgado comarcal", pues podría dar la idea de un órgano jurisdiccional menor, que, por otra parte, no tendría lógica en una ciudad como Colonia, ni de opciones que puedan conducir a la jurisdicción civil lcomo "tribunal de primera instancia"), pues sabemos que se trata de una causa penal. Tras el debate generado en la sesión se llegó al consenso de que una opción adecuada sería aplicar una técnica de traducción ${ }^{17}$ híbrida, a saber, mantener el préstamo en el texto meta (Amtsgericht, ya que es en realidad donde tiene que presentarse el destinatario y, por tanto, se le facilita así su identificación ${ }^{18}$ I seguido de una amplificación (tribunal ${ }^{19}$ penal de primera instancia) o una descripción (simplemente, tribunal municipal) con el objeto de que el término del órgano jurisdiccional alemán no le resulte completamente opaco al lector.

\section{CONCLUSIONES}

Los estudiantes que han realizado esta actividad suelen coincidir en que, a pesar de la dedicación y el tiempo que requiere lespecialmente si cuentan con escasos conocimientos jurídicos previos, como suele ser la normal, este ejercicio de textología y derecho comparados comporta ventajas incuestionables a la hora de poder desarrollar la competencia en traducción jurídica y, por consiguiente, tomar decisiones de traducción con mucha mayor fundamentación. Al basar su marco de toma de decisiones

\footnotetext{
${ }^{14}$ Órgano judicial de primera instancia de la jurisdicción ordinaria (civil y penal); en materia penal, se encarga del enjuiciamiento de los delitos que no son competencia del Landgericht ni del Oberlandesgericht, está integrado por un juez penal y un tribunal de jueces legos, y puede imponer penas privativas de libertad no superiores a cinco años (síntesis de la entrada correspondiente, Alpmann Brockhaus, 2004).

15 Entrada disponible en https://es.pons.com/traducci\%C3\%B3n?q=Amtsgericht\&l=dees\&in=\&lf=de (última consulta: 15 de septiembre de 2017).

16 Inter-Active Terminology for Europe, base de datos de referencia para la Unión Europea, disponible en http://iate.europa.eu/ (búsqueda realizada el 15 de septiembre de 2017).

17 Para conocer más sobre las técnicas de traducción aplicadas a la traducción jurídica, ver Holl (2012) y Orozco (2014), por ejemplo.

${ }^{18}$ Kelly (1998, p. 37) alerta de esta interrelación entre el contenido de un texto y otros elementos paratextuales en la traducción turística, que puede ser perfectamente extrapolable a otros campos, como, en este caso, al jurídico.

19 Como se ha visto en su definición, las causas penales enjuiciadas en un Amtsgericht las dirime un tribunal formado por un juez de carrera y dos jueces legos (Laienrichter, también llamados Schöffen), por lo que no resulta tan apropiado usar el término español juzgado, que se refiere a un órgano unipersonal.
} 
sobre conocimientos y destrezas adquiridos por sí mismos, reduciéndose así su dependencia inicial de las (incompletas) herramientas lexicográficas y terminológicas más habituales en el ámbito de la traducción jurídica alemán-español y del sempiterno ly arriesgadol recurso a la literalidad en esta especialización, los estudiantes cobran consciencia de su proceso de adquisición, desarrollo y consolidación de competencia en traducción jurídica. Al extrapolarse este método de trabajo basado en el análisis pretraductológico y el género textual a otros tipos de texto u otros encargos basados en el mismo tipo de texto, van identificando las relaciones y aplicaciones de destrezas y conocimientos ya adquiridos, ofreciendo un producto de mayor calidad y mejorando ostensiblemente sus procesos de traducción especializada, lo que repercute muy positivamente en la autoconfianza, la autoestima y la motivación del traductor jurídico novel.

\section{REFERENCIAS}

Alcaraz, E. \& Hughes, B. (2002). Legal Translation Explained. Mánchester: St. Jerome.

Alpmann Brockhaus Fachlexikon Recht (2004). Münster y Mannheim: Alpmann \& Schmidt Juristische Lehrgänge y Bibliographisches Innstitut \& F.A. Brockhaus.

Becher, H. J. \& Schülter-Ellner, C. (2017). Wörterbuch Recht, Wirtschaft, Politik. Deutsch-Spanisch (2ª ed.). Múnich: Beck.

Bhatia, V. K. (1993). Analysing genre: Language use in profesional settings. Londres: Longman.

Borja, A. (2013). A genre analysis approach to the study of the translation of court documents. Linguistica Antverpiensia. New Series - Themes in Translation Studies, 12, 33-53. Recuperado de https://goo.gl/uWegdS

Calvo, E. (2015). Scaffolding translation skills through situated training approaches: progressive and reflective methods. The Interpreter and Translator Trainer, 9(3), 306-322. doi: https://doi.org/10.1080/1750399X.2015.1103107

Calvo, E. \& Ortega, J. M. (2010). Bases teóricas y estrategias para inhibir el literalismo en la traducción jurídica. En J. L. Cifuentes Honrubia, A. Gómez González-Jover, A. Lillo, \& F. Yus Ramos (Coords.), Los caminos de la lengua. Estudios en homenaje a Enrique Alcaraz Varó (pp. 63-81). San Vicente del Raspeig: Servicio de Publicaciones de la Universidad de Alicante.

Campos, N. (2017). La traducción de un contrato de trabajo (francés-español). Caracterización del discurso jurídico en francés y en español y propuesta de explotación didáctica en el aula. Sendebar, 28, 71-93. Recuperado de https://goo.gl/Dw5L9M

Cao, D. (2014). Teaching and learning legal translation. Semiotica, 201, 103-119. doi: https://doi.org/10.1515/sem-2014-0022

Cobos, I. (2012). Análisis contrastivo del discurso jurídico español-alemán. Alfinge, 24, 31-54. Recuperado de https://goo.gl/datxr9

De las Heras, M. (2015). La traducción en la adopción internacional. Propuesta de análisis pretraductológico de un expediente de adopción internacional tramitado entre España y la India: la certificación registral de dominio española. (Tesis doctoral, Universidad de Granada). Recuperado de https://hera.ugr.es/tesisugr/25636327.pdf

EMT Expert Group (2009). Competences for professional translators, experts in multilingual and multimedia communication. Bruselas: Dirección General de Traducción de la Comisión Europea. Recuperado de https://goo.gl/ebjitR

Facultad de Humanidades de la Universidad Pablo de Olavide. (2010). VERIFICA GTel: Memoria para la verificación del Grado en Traducción e Interpretación de la Universidad Pablo de Olavide. Recuperado de https://goo.gl/2NxxDm

Holl, I. (2011). Die Kontrastive Textsortenanalyse als Vorstufe zur Übersetzung von Rechtstexten: Deutsche und Spanische Scheidungsurteile im Vergleich. Revista de Lingüística y Lenguas Aplicadas, 6, 195-207. doi: https://doi.org/10.4995/rlyla.2011.903

Holl, I. (2012). Técnicas para la traducción jurídica: Revisión de diferentes propuestas, últimas tendencias. Hermeneus. Revista de Traducción e Interpretación, 14, 1-17. Recuperado de https://goo.gl/u2tEp8

Hurtado Albir, A. (2007). Competence-based Curriculum Design for Training Translators. The Interpreter and Translator Trainer, 1(2), 163-195. doi: https://doi.org/1750399X.2007.10798757 
Kelly, D. (1998). The translation of texts from the tourist sector: textual conventions, cultural distance and other constraints. TRANS, 2, 33-42. doi: http://dx.doi.org/10.24310/TRANS.1998.v0i2.2354

Kelly, D. (2007). Translator competence contextualized. Translator training in the framework of higher education reform: in search of alignment in curricular design. En D. Kenny \& K. Ryou (Eds.) Across Boundaries: International Perspectives on Translation Studies (pp. 128-142). Cambridge: Cambridge Scholars Publishing.

Orozco, M. (2014). Propuesta de un catálogo de técnicas de traducción: la toma de decisiones informada ante la elección de equivalentes. Hermeneus. Revista de Traducción e Interpretación, 16, 233-264. Recuperado de https://goo.gl/qA2mXL

Orts, M. Á. (2017). El género textual en dos culturas jurídicas: análisis pretraductológico de las decisiones judiciales en inglés y en español. Revista de Llengua i Dret, Journal of Language and Law, 67, 220-236. doi: http://dx.doi.org/10.2436/rld.i67.2017.2882

PACTE (2000). Acquiring translation competence: hypotheses and methodological problems of a research project. En Beeby, A., Esinger, D. y Presas, M. (Eds.) Investigating Translation (pp. 99-106). Ámsterdam: John Benjamins.

Piecychna, B. (2013). Legal Translation Competence in the Light of Translational Hermeneutics. Studies in Logic, Grammar and Rhetoric, 34(1), 141-159. doi: http://dx.doi.org/10.2478/slgr-2013-0027

Prieto, F. (2002). Beyond The Confines of Literality: A Functionalist Approach to the Sworn Translation of Legal Documents. Puentes, 2, 27-35. Recuperado de https://goo.gl/rixRyR

Prieto, F. (2011). Developing Legal Translation Competence: An Integrative Process-Oriented Approach. Comparative Legilinguistics - International Journal for Legal Communication, 5, 7-21. doi: http://dx.doi.org/10.14746/cl.2011.5.01

Prieto, F. (2013). ¿Qué estrategias para qué traducción jurídica?: por una metodología integral para la práctica profesional. En I. Alonso Araguás, J. Baigorri Jalón \& H. Campbell (Eds.), Translating the Law. Theoretical and Methodological Issues [Traducir el Derecho. Cues-tiones teóricas y metodológicas] (pp. 87-106). Granada: Comares.

Scarpa, F. \& Orlando, D. (2017). What it takes to do it right: an integrative EMT-based model for legal translation competence. The Journal of Specialised Translation, 27, 21-42. Recuperado de https://goo.gl/3DmWLh

Soriano, G. (2004). La traducción de crisis matrimoniales entre España e Irlanda: un estudio jurídico-traductológico (Tesis doctoral inédita). Universidad de Granada, Granada.

Vigier Moreno,F. J. (2010). La traducción y la interpretación juradas en Alemania. En R. López-Campos, C. Balbuena \& M. Álvarez (Eds.), Traducción y modernidad. Textos científicos, jurídicos, económicos y audiovisuales (pp. 111-121). Córdoba: Universidad de Córdoba.

Way, C. (2014). Structuring a Legal Translation Course: A Framework for Decision-Making in Legal Translator Training. En L. Cheng, K. Kui Sin \& A. Wagner (Eds.), The Ashgate Handbook of Legal Translation (pp. 133-152). Farnham: Ashgate.

Way, C. (2016). The Challenges and Opportunities of Legal Translation and Translator Training in the 21st Century. International Journal of Communication, 10, 1009-1029. Recuperado de https://goo.gl/ULRx3M

Valderrey, C. (2017). Modelos textuales multinivel y desarrollo del saber en Derecho en la formación de traductores. Sendebar, 28, 53-70. Recuperado de https://goo.gl/La53PM

Wiesmann, E. (1999). Berücksichtigung von Textsortenkonventionen bei der Übersetzung von Rechtstexten am Beispiel der Übersetzung italienischer Atti di citazione ins Deutsche. En P. Sandrini (Ed.) Übersetzen von Rechtstexten. Fachkommunikation im Spannungsfeld zwischen Rechtsordnung und Sprache (pp. 155-182). Tubinga: Narr.

(c) Los autores. Este artículo es publicado por la Revista Digital de Investigación en Docencia Universitaria del Área de Institutional Research and Effectiveness de la Dirección de Aseguramiento de la Calidad, Universidad Peruana de Ciencias Aplicadas. Este es un artículo de acceso abierto, distribuido bajo los términos de la LicenciaCreativeCommons Atribución-Compartirlgual 4.0 Internacional.l http://creativecommons.org/licenses/bysa/4.0/l, que permite el uso no comercial, distribución y reproducción en cualquier medio, siempre que la obra original sea debidamente citada. 


\section{APÉNDICE A \\ AMTSGERICHT KÖLN \\ - GESCHÄFTSSTELLE-}

-223- Amtsgericht Köln, 50922 Köln

Herrn

Fernando González [Nombre ficticio del destinatario]

Höninger Weg 115 [Dirección elegida aleatoriamente]

50969 Köln

\section{Ladung}

Sehr geehrter Herr González,

in Ihrer Strafsache wegen Beleidigung werden Sie auf Anordnung des Gerichts zur Hauptverhandlung geladen.

Der Termin findet statt am

Dienstag, 06.05.2017, 13:15 Uhr,

\section{Etage, Sitzungsaal 247, Luxemburger Str. 101, 50939 Köln}

Der Beschluss über die Eröffnung des Hauptverfahrens ist beigefügt.

Im Falle Ihres unentschuldigten Ausbleiblens wird Ihre (polizeiliche) Vorführung angeordnet oder ein Haftbefehl erlassen.

Am Eingang des Gerichts finden Einlasskontrollen statt. Dort können Wartzeiten entstehen. Richten Sie sich bitte hierauf ein, damit Sie rechtzeitig im Gerichtssaal sein können. Führen Sie bitte ein gültiges Ausweispapier (Personalausweis, Reisepass oder einen gleichgestellten Identitätsnachweis) mit.

Sofern Sie aus zwingenden persönlichen Gründen - z.B. ernstahfte Erkrankung - nicht kommen können, teilen Sie dies bitte umgehend mit. Berufliche Verpflichtungen stellen grundsätzlich keinen ausreichenden Verhinderungsgrund dar. Ihr Arbeitgeber ist verpflichtet, Ihnen die Termin an der Hauptverhandlung zu ermöglichen. Bei Erkränkung ist regelmäßig die Vorlage eines ärtzlichen Attestes erforderlich, aus dem sich die Erkrankung und insbesondere die Verhandlungsunfähigkeit ergeben. Eine Bescheinigung lediglich über die Arbeitsunfähigkeit reicht nicht aus. Bitte geben Sie auch die voraussichtliche Dauer Ihrer Verhinderung und für Rückfragen Ihrer Telefonnummer an. Wenn wir Ihre Absage nicht bestätigen, müssen Sie zum Termin kommen.

Beachten Sie bitte unsere weiteren Hinweise und bringen Sie dieses Schreiben zum Termin mit.

Mit freundlichen Grüßen,

Zimmermann [nombre ficticio de la funcionaria de Justicia]

Juztizbeschäftigte 